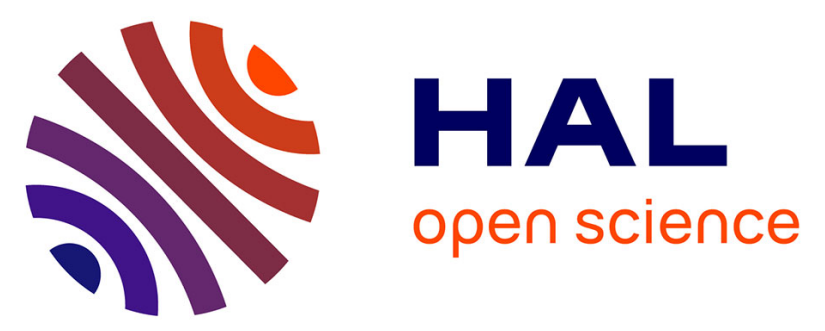

\title{
Enhanced oxidative stress in adipose tissue from diabetic mice, possible contribution of glycated albumin
}

Florence Boyer, Nicolas Diotel, Dorothée Girard, Philippe Rondeau, M.

Faadiel Essop, Emmanuel Bourdon

\section{- To cite this version:}

Florence Boyer, Nicolas Diotel, Dorothée Girard, Philippe Rondeau, M. Faadiel Essop, et al.. Enhanced oxidative stress in adipose tissue from diabetic mice, possible contribution of glycated albumin. Biochemical and Biophysical Research Communications, 2016, 473 (1), pp.154-160. 10.1016/j.bbrc.2016.03.068 . hal-01692746

\section{HAL Id: hal-01692746 \\ https://hal.univ-reunion.fr/hal-01692746}

Submitted on 6 Feb 2018

HAL is a multi-disciplinary open access archive for the deposit and dissemination of scientific research documents, whether they are published or not. The documents may come from teaching and research institutions in France or abroad, or from public or private research centers.
L'archive ouverte pluridisciplinaire HAL, est destinée au dépôt et à la diffusion de documents scientifiques de niveau recherche, publiés ou non, émanant des établissements d'enseignement et de recherche français ou étrangers, des laboratoires publics ou privés. 


\title{
Enhanced oxidative stress in adipose tissue from diabetic mice, possible contribution of glycated albumin
}

\author{
Florence Boyer $^{\text {a, b }}$, Nicolas Diotel ${ }^{\text {a, b }}$, Dorothée Girard ${ }^{\text {a, b }}$, Philippe Rondeau ${ }^{\text {a, b }}$, \\ M. Faadiel Essop ${ }^{c}$, Emmanuel Bourdon ${ }^{\text {a, b, * }}$ \\ a Inserm, UMR 1188 Diabète athérothrombose Thérapies Réunion Océan Indien (DéTROI), plateforme CYROI, Sainte-Clotilde F-97490, France \\ ${ }^{\mathrm{b}}$ Université de La Réunion, UMR 1188, Sainte-Clotilde F-97490, France

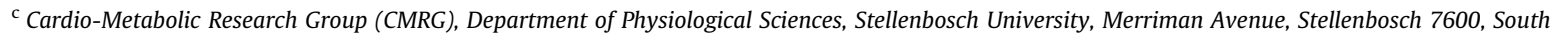 \\ Africa
}

\section{A B S T R A C T}

Although enhanced oxidative stress and proteotoxicity constitute major contributors to the pathogenesis of multiple diseases, there is limited understanding of its role in adipose tissue. Here, we aimed at evaluating oxidative stress biomarkers in adipocytes from diabetic/obese $\mathrm{db} / \mathrm{db}$ mice. The current study revealed that reactive oxygen species production was upregulated in adipocytes, together with lipid peroxidation 4-hydroxynonenal accumulation, and altered proteolytic and antioxidant activities. In parallel, acute exposure of 3T3L1 adipocyte cell lines to glycated albumin (known to be enhanced with diabetes) also elicited intracellular free radical formation. Our data provide novel insights into redox and proteolytic homeostasis in adipocytes.

\section{Introduction}

Oxidative stress is defined as "an imbalance between oxidants and anti-oxidants in favor of the oxidants, leading to a disruption of redox signaling and control and/or molecular damage" [1]. While reactive oxygen species (ROS) can act as signaling molecules, excessive amounts can induce lipid, DNA and protein oxidative damage thereby altering structure and function [1]. Under such circumstances antioxidant defences and/or repair processes can fail resulting in an imbalance in favor of greater intracellular ROS availability. However, under such conditions proteolytic mechanisms including the ubiquitin proteasome system (UPS) are activated to remove damaged, oxidized proteins [2].

Oxidative stress is robustly implicated in disease onset and increasing evidence implicates it in the development of insulin resistance $[3,4]$. Diabetes is a major health problem that is usually associated with obesity, together with hyperglycemia and

Abbreviations: AGE, advanced glycation end products; DHE, dihydroethidium GPX, glutathione peroxidase; 4HNE, 4-hydroxynonenal; PBS, saline phosphate buffer; PUFA, polyunsaturated fatty acids; ROS, reactive oxygen species; SOD, superoxide disumutase.

* Corresponding author. DéTROI - Université de la Réunion, CYROI 2, rue Maxime Rivière, BP 80005 - 97491 Sainte Clotilde Cedex La Réunion , France.

E-mail address: Emmanuel.bourdon@univ-reunion.fr (E. Bourdon). advanced glycation endproducts (AGEs) formation. The concept of redox imbalance (in fat tissues) as an instigator of adipocyte dysfunction with obesity is a recent phenomenon [5]. For example, oxidative stress impaired systemic insulin sensitivity and played a causative role in the development of insulin resistance in adipose tissues $[4,6]$. Here the role of the proteasome remains poorly understood and recent evidence established an important function in controlling redox homeostasis and in the degradation of oxidized proteins [7]. Moreover, despite increased evidences of enhanced AGEs formation in the diabetes/obesity context, AGE involvement in adipocyte pathophysiology onset remains poorly understood [8]. As little is known regarding alterations in oxidative stress and protein homeostasis in adipose tissues, this study investigated redox homeostasis in adipocytes from the leptin receptor-deficient $\mathrm{db} / \mathrm{db}$ transgenic mouse strain. To gain additional mechanistic insights, we also established an in vitro experimental protocol to assess the deleterious effects of hyperglycemia and albumin-AGE on 3T3L1 cells by monitoring intracellular free radical formation.

\section{Materials and methods}

\subsection{Animals}

C57BLKs/J+/Lepr ${ }^{\mathrm{db}}$ mice $(\mathrm{db} /+)$ were obtained from Charles 
River Laboratories (Wilmington MA). Male heterozygous $\mathrm{db} /+$ and homozygous C57BLKs/J/Lepr ${ }^{\mathrm{db}} /$ Lepr $^{\mathrm{db}}(\mathrm{db} / \mathrm{db})$ mice $(\mathrm{n}=10$ per group) were housed under constant temperature $\left(21^{\circ} \pm 2{ }^{\circ} \mathrm{C}\right)$, humidity $(50 \% \pm 5 \%)$ and a 12-h light-dark cycle for a period of 12 weeks. Food and water were available ad libitum and all experimental procedures were conducted in compliance with animal protocols approved by the Animal Ethics Committee of Cyclotron Réunion Océan Indien (CYROI) (Project \#01268.01).

\subsection{Tissue collection and biochemical analyses}

Twelve-week old mice were fasted overnight, weighed, anesthetized and euthanized before fasting blood glucose levels measurement using the OneTouch ${ }^{\circledR}$ Ultra Blood Glucose Monitoring System (Lifescan). Blood was collected by cardiac puncture into EDTA tubes (BD Vacutainer ${ }^{\circledR}$ ) and total proteins, cholesterol, albumin, fructosamine and triglycerides levels were determined using a clinical Biochemistry automated Cobas C501 analyzer (Roche Diagnostics). Epididymal adipose tissues were excised, snap frozen and stored at $-80{ }^{\circ} \mathrm{C}$ prior to analysis. Previously collected and stored epididymal adipose tissues were homogenized with a TissueLyser II (Qiagen) in a phosphate buffer $\left(\mathrm{KH}_{2} \mathrm{PO}_{4}(100 \mathrm{mM})\right.$, DTT (1 mM), and EDTA (2 mM), pH 7.4). After centrifugation (5000 g/ min for $10 \mathrm{~min}$ ), the supernatant was used for protein quantification, carbonyl and enzymatic assays.

\subsection{Immunohistochemistry and oxidative stress staining}

For immunohistochemistry, adipose tissues from $\mathrm{db} /+$ and $\mathrm{db} /$ $\mathrm{db}$ mice were collected and fixed in $4 \%$ paraformaldehyde in PBS. Paraffin sections ( $7 \mu \mathrm{m}$ ) were prepared using a microtome (Thermo Scientific, Shandon ${ }^{\mathrm{TM}}$ Finesse $^{\mathrm{TM}} \mathrm{ME}+$ ) and thereafter deparaffinized and rehydrated. Antigen retrieval was performed in sodium citrate buffer ( $\mathrm{pH} 6 ; 0.01 \mathrm{M}$ ) and sections were incubated overnight at room temperature with the 4-HNE antibody (1/100; Ref\# ab46545; Abcam, Cambridge MA) in PBS-Triton containing 1\% BSA. The next day sections were washed in PBS-Triton and incubated for $1 \mathrm{~h} 30$ with secondary antibody (Alexa Fluor goat anti-rabbit 594; 1:200; Invitrogen Molecular Probes, Eugene OR). Sections were finally counterstained with DAPI and slides mounted with Vectashield anti-fading medium (H-1000, Vector Laboratories, Burlingame CA).

For ROS imaging, unfixed adipose tissues were sampled and frozen at $-80^{\circ} \mathrm{C}$ before being embedded in OCT (Tissue Tek, Sakura, Torrance, CA) and cut at $10 \mu \mathrm{m}$ thickness using a conventional cryotome (Thermo Scientific, Shandon ${ }^{\mathrm{TM}}$ Cryotome FE, France). Slides were defrosted for $1 \mathrm{~h}$ at room temperature in a humidified chamber and subsequently incubated with $2 \mu \mathrm{M}$ DHE (dissolved in PBS; Sigma-Aldrich, Ref: D7008, France) in a light-protected humidified chamber at $37{ }^{\circ} \mathrm{C}$ for $30 \mathrm{~min}$. Slides were subsequently washed twice in PBS and mounted with Vectashield anti-fading medium (Vector Laboratories, Burlingame CA).

\subsection{Microscopy}

Prepared slides were viewed with a bright field/epifluorescence microscope Nikon Eclipse 80i equipped with a Hamamatsu ORCAER digital camera (Hamamatsu Photonics, Japan). For $4 \mathrm{HNE}$ immunohistochemistry and ROS staining, pictures were acquired using the Nikon software with similar exposure times between $\mathrm{db} /$ + and $\mathrm{db} / \mathrm{db}$ sections. Micrographs were obtained in tiff format and adjusted for light and contrast before being assembled on plates in Adobe Photoshop CS4 (extended version 11.0).

\subsection{Thiol number determination}

Thiol groups were measured according to Ellman's assay using 5,5'-dithiobis, 2-nitrobenzoic acid (DTNB) [9]. A standard curve was generated for each assay and here we used 10-100 nmol of $\mathrm{L}_{-}$ cysteine (Sigma-Aldrich). Briefly, $100 \mu \mathrm{L}$ of tissue samples (in $0.1 \mathrm{M}$ Tris- $\mathrm{HCl}$, pH 8.0, EDTA $5 \mathrm{mM}$ ) were incubated with three volumes of $0.5 \mathrm{mM}$ DTNB and the free thiol concentration was calculated from absorbance readings $(412 \mathrm{~nm}$ ) with the help of a standard curve. Results are expressed in nmol of free $-\mathrm{SH}$ groups per $\mu \mathrm{g}$ protein.

\subsection{Enzymatic activity determination}

SOD activity was assayed by monitoring the rate of acetylated cytochrome $\mathrm{c}$ reduction by superoxide radicals generated by the xanthine/xanthine oxidase system. Measurements were performed in a reagent buffer (xanthine oxidase, xanthine $(0.5 \mathrm{mM})$, cytochrome c (0.2 mM), KH2PO4 (50 mM), EDTA (2 mM), pH 7.8) at $25{ }^{\circ} \mathrm{C}$. The specific Manganese-SOD (Mn-SOD) activities were determined in the same condition after incubation of samples with $\mathrm{NaCN}(1 \mathrm{mM})$ which inhibits $\mathrm{Cu} / \mathrm{Zn}-\mathrm{SOD}$ activities. Assays were monitored by spectrophotometry at $560 \mathrm{~nm}$. SOD activities were calculated using a calibration standard curve of SOD (up to 6 unit/ $\mathrm{mg}$ ). Total Mn-SOD and resulting $\mathrm{Cu} / \mathrm{Zn}$-SOD activities were expressed as international catalytic units per mg of proteins.

Glutathione peroxidase (GPX) activity was determined with cumene hydroperoxide as substrate [10]. The rate of glutathione oxidized by cumene hydroperoxide $(6.5 \mathrm{mM})$ was evaluated by measuring NADPH (0.12 mM in Tris buffer) absorbance at $340 \mathrm{~nm}$. Here the reaction buffer is composed of $\mathrm{NaCN}(10 \mathrm{mM})$, reduced glutathione $(0.25 \mathrm{mM})$ and glutathione reductase $(1 \mathrm{U} / \mathrm{ml})$ in Tris buffer (50 mM, pH 8). GPX activity was expressed as international units per gram of proteins.

The catalase activity assay was performed on $40 \mu \mathrm{g}$ of protein lysate in $25 \mathrm{mM}$ Tris- $\mathrm{HCl}(\mathrm{pH} 7.5)$. Blanks were measured at $240 \mathrm{~nm}$ just before adding $80 \mu \mathrm{L}$ of $\mathrm{H}_{2} \mathrm{O}_{2}$ (10 mM final) to start the reaction. Catalase activity was determined by measuring the absorbance at $240 \mathrm{~nm}$ and calculated using a standard calibration curve constructed by increasing catalase amounts (between 12.5 and 125 units $/ \mathrm{ml}$ ). Catalase activity was expressed as international catalytic units per mg of proteins.

Proteasome activity measurements, i.e. chymotrypsin-like, trypsin-like, and caspase-like activities of the proteasome were assayed using fluorogenic peptides (Sigma-Aldrich, St Louis): SucLeu-Leu-Val-Tyr-7-amido-4-methylcoumarin (LLVYMCA at $25 \mathrm{mM}$ ), N-t-Boc-Leu-Ser-Thr-Arg-7-amido-4-methylcoumarin (LSTR-MCA at $40 \mathrm{mM}$ ) and N-Cbz-Leu-Leu-Glu-bnaphthylamide (LLE-NA at $150 \mathrm{mM}$ ), respectively, as described previously [11].

\section{7. $3 T 3$ L1 cell line}

3T3L1 cells were cultured in completed DMEM medium 10\% FBS, penicillin $(100 \mathrm{U} / \mathrm{ml})$, streptomycin $(100 \mathrm{U} / \mathrm{ml})$ and L-glutamine $(2 \mathrm{mM})$ and grown in a $5 \% \mathrm{CO}_{2}$ incubator at $37{ }^{\circ} \mathrm{C}$. Prior to treatments, 3T3 L1 cells were cultured in DMEM containing 1\% FBS in 96 -well plates (10 000 cells/well) for $24 \mathrm{~h}$ to reach about $75 \%$ confluency. At this stage cells were treated for $1 \mathrm{~h}$ under simulated normoglycemic conditions ( $5 \mathrm{mM}$ glucose) in the absence (NG) or presence of $80 \mu \mathrm{M}$ of native albumin $\left(\mathrm{HSA}_{\mathrm{G} 0}\right)$, glycated albumin $\left(\mathrm{HSA}_{\mathrm{MGO}}\right)$ versus simulated hyperglycemic conditions $(25 \mathrm{mM}$ glucose; $H G)$. 


\subsection{Cell viability and intracellular ROS determination}

To assess cell viability, we employed the crystal violet DNA staining assay that was adapted from Saotome et al. [12]. The medium was removed after treatments, cells were washed twice, and then $200 \mu \mathrm{L}$ of $5 \mathrm{mg} / \mathrm{mL}$ crystal violet solution was added to each well and incubated for $15 \mathrm{~min}$. The plate was carefully washed $(5 \mathrm{x})$ by immersion in a large beaker with water. $100 \mu \mathrm{L}$ of $1 \%$ sodium dodecyl sulphate was then added to each well to solubilize the stain and absorbance read at $570 \mathrm{~nm}$. Results were expressed as percentage of untreated cells. Intracellular oxidative stress in treated 3T3L1 cells was evaluated by using the dichlorofluorescein diacetate (DCFH-DA) probe as described previously [13]. Results were expressed as percentage of fluorescence in relation to the control.

\subsection{Dot-blot analysis}

Each tissue homogenate sample (about $30 \mu \mathrm{g}$ protein) was spotted onto a dry nitrocellulose membrane by using a grid from pipette tip rack as a guide. The membrane was air-dried for $15 \mathrm{~min}$ and was washed twice in acetic acid for $2 \mathrm{~min}$. The membrane was initially blocked with PBS/0.1\% Tween $20(\mathrm{v} / \mathrm{v}) / \mathrm{milk} 5 \%$ for $3 \mathrm{~h}$ at room temperature and then sequentially probed for another $3 \mathrm{~h}$ with a primary antibody directed against 4 HNE (1:1000; Ref\# ab46545; Abcam, Cambridge MA). This was followed by secondary antibody incubation for at least $1 \mathrm{~h}(1: 2000$; Peroxidase AffiniPure Goat Anti-Rabbit IgG $(\mathrm{H}+\mathrm{L})$; Jackson Immunoresearch Laboratories Inc; Ref\# 111-035-003). Between each step, membranes were washed three times with PBS/0.1\% Tween $20(\mathrm{v} / \mathrm{v})$. Detection was performed using the enhanced chemiluminescence reagent $\left(E C{ }^{\circledR}\right.$, GE Healthcare). Signal intensities were quantified using the freeware ImageJ (version 1.32j) available from the internet website: http://rsb.info.nih.gov/ij/.

\subsection{Statistical analysis}

Data are expressed as the mean \pm standard deviation (SD) from at least three experiments. Figures and pictorial representations are representative of at least three independent observations. Statistical significance was determined using the Student's t-test, with a pvalue $<0.05$ required for significance.

\section{Results}

\subsection{Biochemical characterization of $\mathrm{db} / \mathrm{db}$ diabetic mice}

Mice were sacrificed at 12 weeks of age and body weights

Table 1

Analytical characteristics of diabetic $(\mathrm{db} / \mathrm{db})$ and control heterozygous $(\mathrm{db} /+)$ mice.

\begin{tabular}{lll}
\hline & $\mathrm{db} /+$ & $\mathrm{db} / \mathrm{db}$ \\
\hline $\mathrm{n}$ & 10 & 10 \\
Body weight $(\mathrm{g})$ & $29.6 \pm 1.2$ & $46.7 \pm 3.3^{* * *}$ \\
EAT $(\mathrm{g})$ & $0.55 \pm 0.1$ & $2.43 \pm 0.21^{* * *}$ \\
Fasting glycemia $(\mathrm{mg} / \mathrm{dL})$ & $56.6 \pm 14.0$ & $315 \pm 66^{* * *}$ \\
HOMA IR & $4.04 \pm 2.54$ & $21.9 \pm 5.1^{* * *}$ \\
Total protein & $41.6 \pm 2.2$ & $48.3 \pm 5.1^{* * *}$ \\
Albuminemia $(\mathrm{g} / \mathrm{L})$ & $29.3 \pm 1.9$ & $31.4 \pm 1.6^{* * *}$ \\
Fructosamine $(\mathrm{mmol} / \mathrm{L})$ & $311 \pm 69$ & $535 \pm 100^{* * *}$ \\
Cholesterol $(\mathrm{mmol} / \mathrm{L})$ & $2.04 \pm 0.23$ & $2.64 \pm 0.51^{* * *}$ \\
Triglycerides $(\mathrm{mmol} / \mathrm{L})$ & $1.27 \pm 0.27$ & $2.31 \pm 0.65^{* * *}$ \\
\hline
\end{tabular}

All clinical, metabolic and oxidative parameters were determined at 12 weeks of age. EAT, epididymal adipose tissue; HOMA-IR, homeostatic model assessment insulin resistance. Values are shown as mean $\pm \mathrm{SD}(\mathrm{n}=10) .{ }^{* *} \mathrm{P}<0.01$ and ${ }^{* * *} \mathrm{P}<0.001$ indicate a significant difference versus $\mathrm{db} /+$ group. together with classic biochemical parameters were measured (refer Table 1). The $\mathrm{db} / \mathrm{db}$ mice displayed an obese phenotype, i.e. a $58 \%$ difference in body weight compared to $\mathrm{db} /+$ controls $(\mathrm{p}<0.001)$. In support, epididymal adipose tissue (EAT) weight was substantially higher in the $d b / d b$ group versus $d b /+$ mice $(p<0.001)$. Despite their relatively young age, $\mathrm{db} / \mathrm{db}$ mice also exhibited significantly enhanced fasting glycemia compared to the heterozygote group, thus confirming diabetic status. In addition, serum fructosamine, cholesterol and triglyceride levels were increased in $\mathrm{db} / \mathrm{db}$ mice compared to controls. The $\mathrm{db} / \mathrm{db}$ mice were also insulin resistant as demonstrated by the 5 -fold increase in the HOMA index versus $\mathrm{db} /$ + mice $(\mathrm{p}<0.001)$.

\subsection{Enhanced ROS production in adipose tissue of $d b / d b$ mice}

We also found enhanced cytosolic superoxide production (DHE probe) in EAT isolated from db/db mice (Fig. 1A). Histological analyses also revealed adipocyte hypertrophy in EAT isolated from the $\mathrm{db} / \mathrm{db}$ mice (data not shown). Despite lower cell numbers in experimentally defined areas, we found significantly more DHE positive cells in EAT isolated from $\mathrm{db} / \mathrm{db}$ versus $\mathrm{db} /+$ mice (Fig. 1B). To further support our DHE data we also evaluated thiol number as a marker of oxidative damage. Here there was a significant decrease of $39 \%$ in thiol number in $\mathrm{db} / \mathrm{db}$ EAT compared to matched controls (Fig. 1C).

\subsection{Increased 4-HNE in adipose tissues of $d b / d b$ mice}

In agreement with our earlier data, there was a much higher accumulation of the lipid peroxidation product $4-\mathrm{HNE}$ in $\mathrm{db} / \mathrm{db}$ adipose tissues as clearly evidenced by the immunohistochemistry staining (Fig. 2A). In addition, dot blot analyses revealed that the 4HNE concentration was significantly up regulated in $\mathrm{db} / \mathrm{db}$ adipose tissue versus respective controls reinforcing the previous data (Fig. 2B and C).

\subsection{Impaired antioxidant activities in adipose tissues isolated from diabetic mice}

$\mathrm{Cu} / \mathrm{Zn}$ and MnSOD enzyme activities were significantly increased $(+38 \%)$ in $\mathrm{db} / \mathrm{db}$ EAT versus $\mathrm{db} /+$ controls (Fig. 3). Interestingly, such enhanced SOD activity was not associated with any adaptive antioxidant enzyme upregulation for catalase or glutathione peroxidase activities. In support, no significant variation in SOD, catalase and gluthatione peroxidase mRNA levels were found when assessed by real-time PCR (data not shown).

\subsection{Proteasomal activities are enhanced in adipose tissue from diabetic mice}

Trypsin-like, chymotrypsin-like activities were evaluated in adipose tissue homogenates using fluorogenic peptides and here a 3- to 4-fold increase was measured in adipose tissues isolated from $\mathrm{db} / \mathrm{db}$ mice (Fig. 3D). In our experimental conditions, no caspaselike activity of the proteasome was detected in EAT.

\subsection{Glycated albumin and hyperglycemia induced oxidative stress in murine adipocytes}

Unpublished data from our group previously revealed that fluorescent AGE, carbonyl levels and glycoxidation of serum albumin were significantly higher in plasma of $\mathrm{db} / \mathrm{db}$ mice, reflecting a general impairment of redox regulation in this group. To gain further insight into the mechanisms whereby redox homeostasis is impaired in adipose tissues of diabetic mice, 3T3 L1 mouse cell lines 

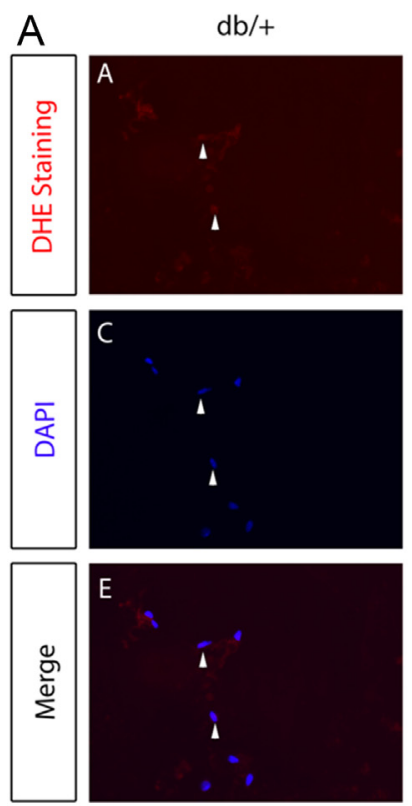
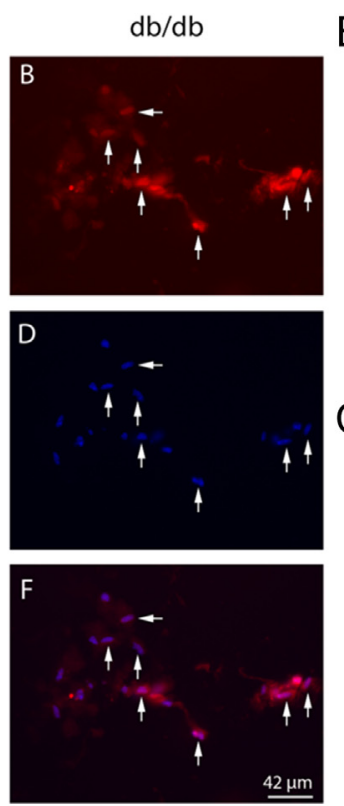

$\mathrm{B}$

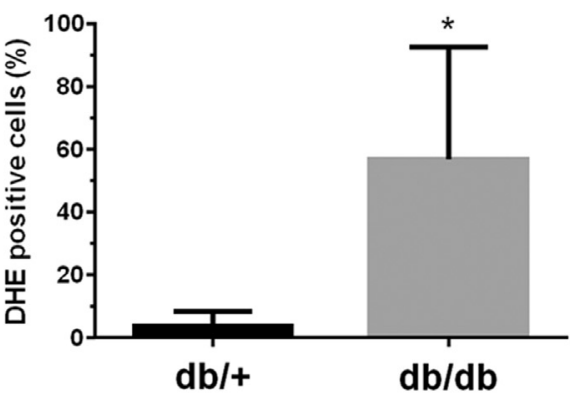

C

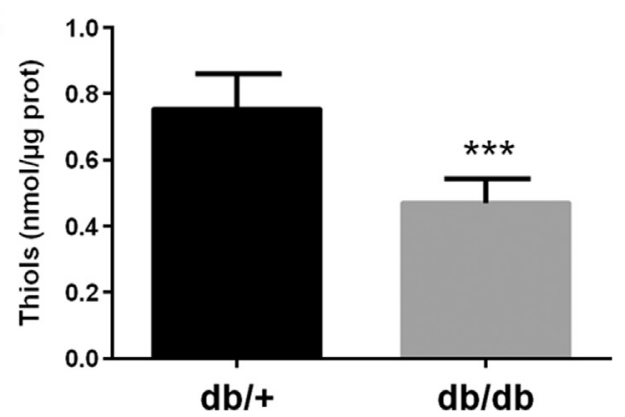

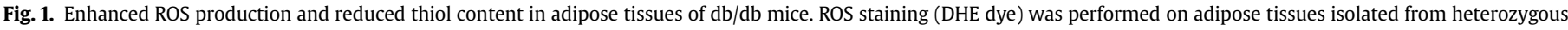

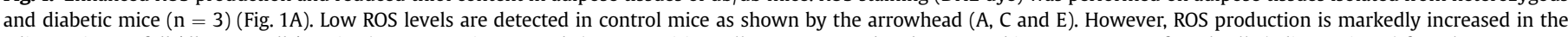

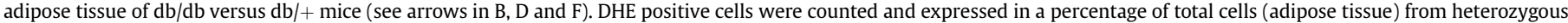

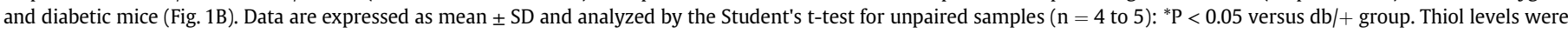

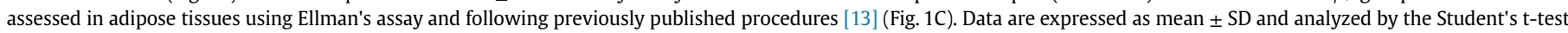
for unpaired samples $(\mathrm{n}=5)$ : ${ }^{* * *} \mathrm{P}<0.001$ versus $\mathrm{db} /+$ group.
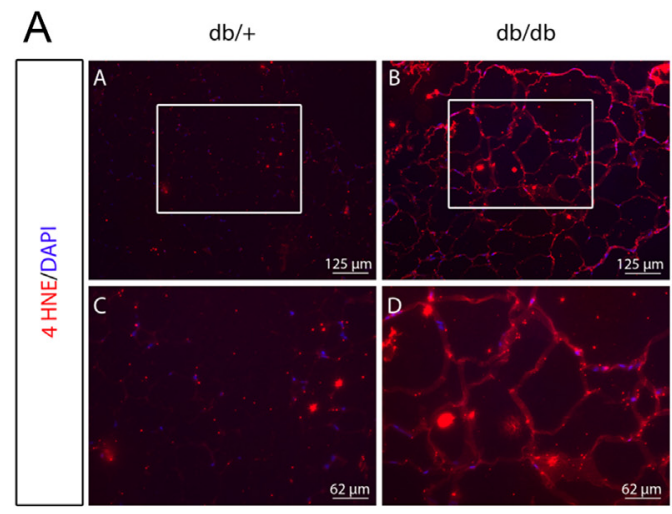

B

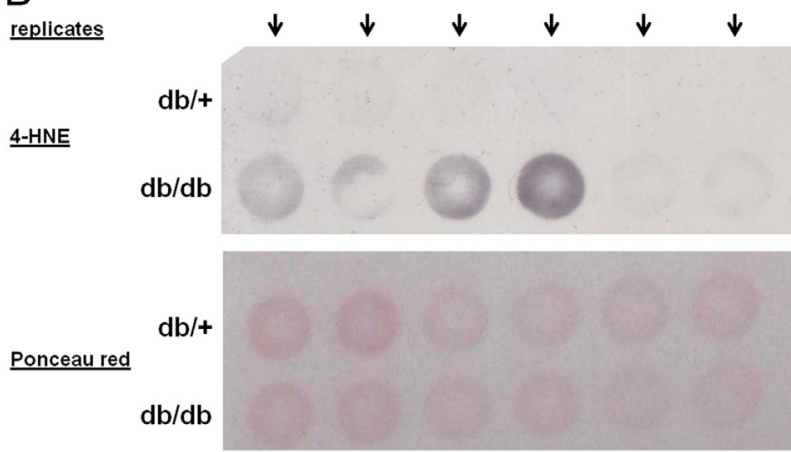

C

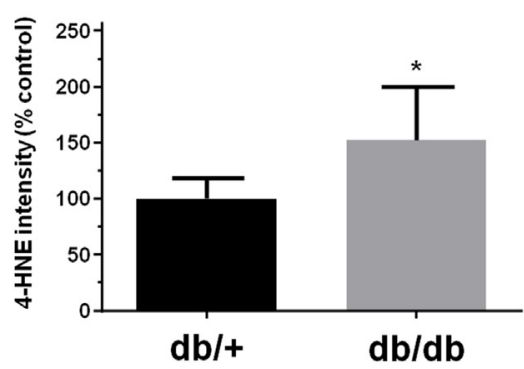

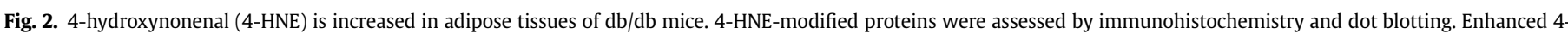

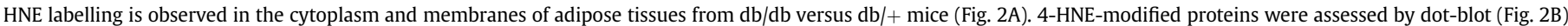

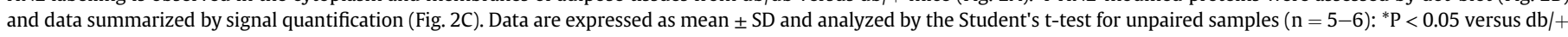
group. 

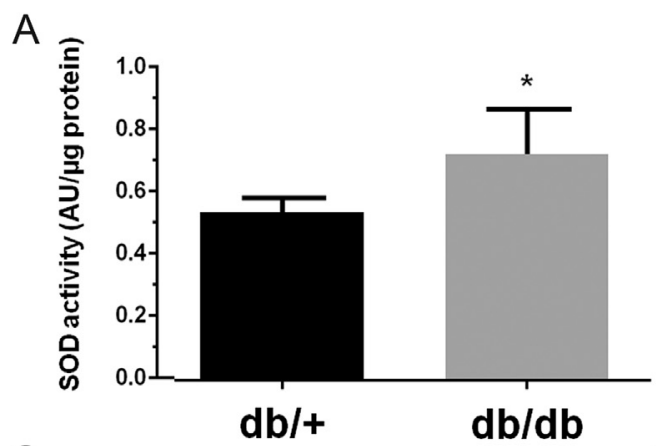

C

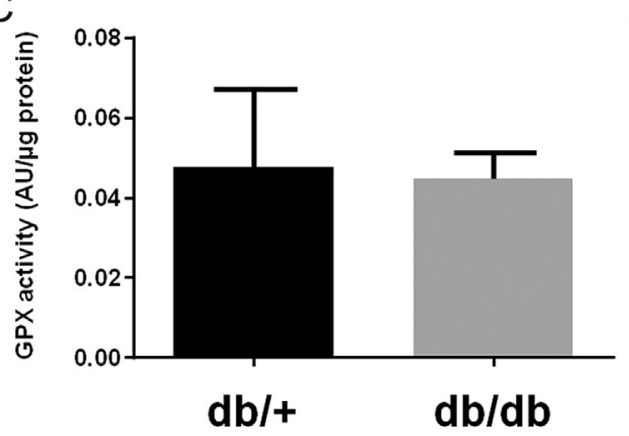

B
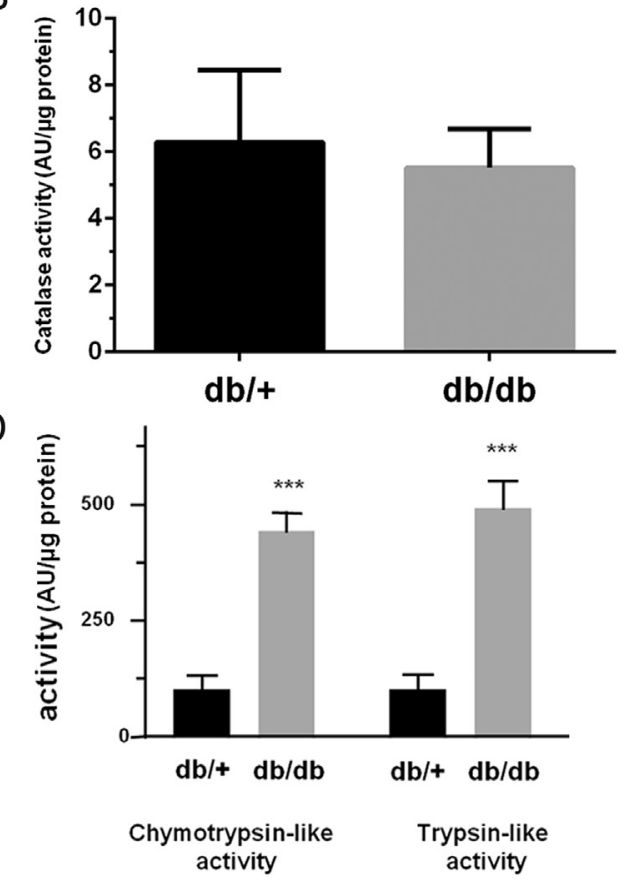

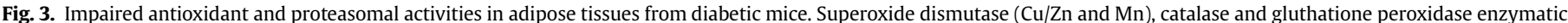

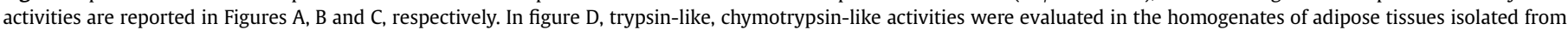

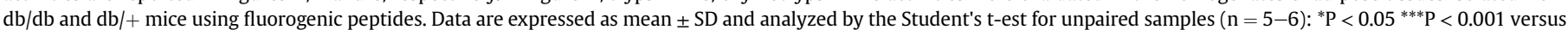
$\mathrm{db} /+$ group.
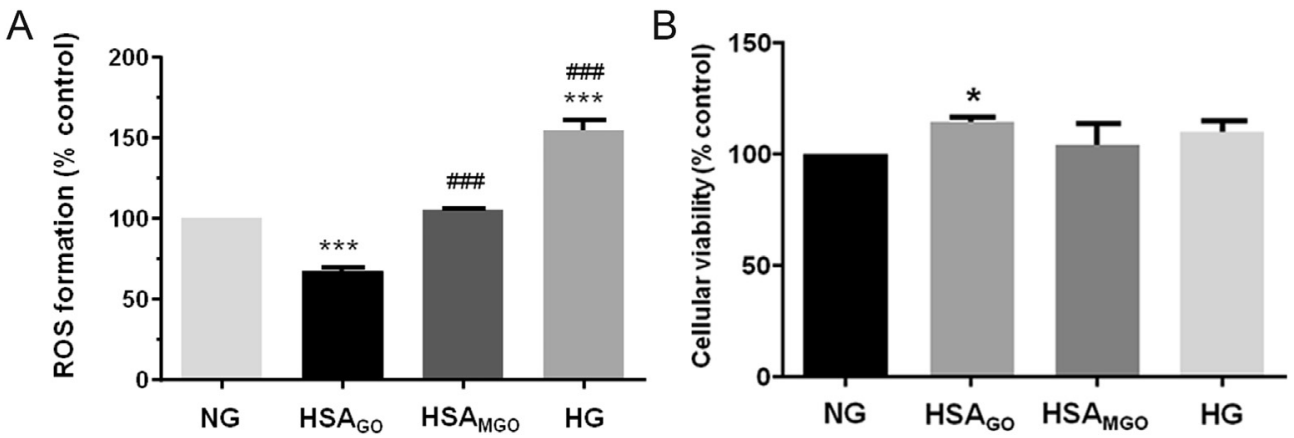

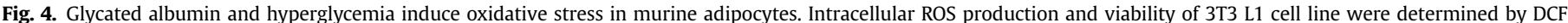

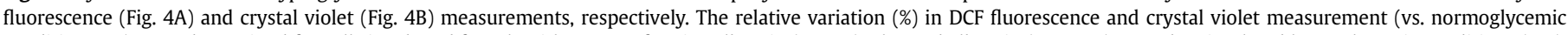

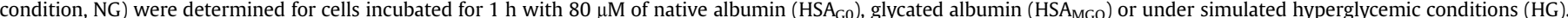

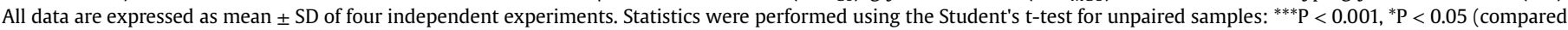
to $\mathrm{NG}$ condition), ${ }^{\# \# \#} \mathrm{P}<0.001$ (compared to $\mathrm{HSA}_{\mathrm{G} 0}$ ).

were incubated under simulated normo- and hyperglycemic conditions \pm native or glycated albumin (Fig. 4). Hyperglycemia and glycated albumin treatment induced a robust increase in intracellular ROS formation ( $+50 \%, \mathrm{p}<0.001 \mathrm{vs}$. NG or $\left.\mathrm{HSA}_{\mathrm{GO}}\right)$. The latter effects were observed in the absence of any toxic impact of hyperglycemic or glycated albumin cellular treatments (Fig. 4B).

\section{Discussion}

An emerging paradigm is that redox imbalances in fat tissue may play a pivotal role in the onset of adipocyte dysfunction with obesity [5]. For example, oxidative stress in fat cells impaired systemic insulin sensitivity and is an early instigator of insulin resistance onset $[4,6]$. However, despite such progress a number of questions remains concerning diabetes-related protein oxidative modifications in adipose tissues. The present study therefore investigated this question and revealed enhanced ROS formation and 4-HNE accumulation together with altered antioxidant enzyme capacity and UPS responses. In support, 3T3L1 adipocytes exposed to glycated albumin also exhibited an altered redox balance. These data are consistent with our previous findings where glycated albumin exposure induced oxidative stress in primary human adipocytes thereby leading to the accumulation of oxidized proteins $[14,15]$.

It is our opinion that antioxidant enzyme activities of SOD, catalase and gluthatione peroxidase provide unique insights into the origins of the enhanced adipocyte ROS formation with diabetes. These data support the concept that enhanced SOD activity (not 
counteracted by elevated catalase and/or gluthathione peroxidase activities) is an early biomarker of increased superoxide production and redox imbalance in adipose tissues of diabetic mice. Indeed, elevated ROS production and oxidative damage were previously observed in the cortexes of SOD overexpressing mice [16]. The impact of increased ROS levels on protein oxidative modifications is supported by the reduction of thiols in adipose tissues of $\mathrm{db} / \mathrm{db}$ mice. The conversion of SH groups into disulfides constitutes one of the early steps of protein oxidation [17]. Thiol reduction can arise from protein succination that occurs due to the reaction of fumarate (Krebs cycle intermediate) with protein cysteine residues [18]. Our results are indeed in full accordance with recent reports showing enhanced succination of thiol groups resulting from mitochondrial stress in adipose tissues of $\mathrm{db} / \mathrm{db}$ mice $[19,20]$. In our $\mathrm{db} / \mathrm{db}$ mice model, oxidative damage at the adipose tissue level were also confirmed by 4-HNE accumulation, an end-product of n-6 PUFAs peroxidation. Protein-HNE adducts were previously described as long-lived "footprints" of lipid peroxidation and recently proposed as a suitable and metastable biomarker for in vivo adipose tissue oxidation and dysregulation [21].

Although the role of the proteasome in adipocytes remains largely unexplored, the few examples present in the literature favor a determinant role in redox homeostasis regulation and cellular differentiation, therefore influencing the development of obesity [22] [7,23]. In the present study, trypsin- and chymotrypsin-like activities were significantly increased in adipose tissues from diabetic mice. In agreement, we recently found enhanced trypsin-like activity and low molecular mass polypeptide 2 (LMP2) subunit expression of the proteasome in human adipose cells exposed to hyperglycemic conditions [24]. Such elevated proteolytic activity may be considered as a defense system triggered by the oxidative stress insult. In support, a model of oxidative stress-dependent regulation of the proteasome was recently proposed where increased proteasomal expression is linked to conditions of persistent and prolonged exposure to oxidative stress [25]. Thus in our experimental system, the proteasome system may be rapidly overwhelmed by oxidative stress and resulted in protein oxidation that accumulates in adipose tissues from diabetic mice.

Although the precise mechanism(s) whereby redox balanced is impaired in diabetic adipose tissues are likely to be multifactorial, our group hypothesized enhanced glycated albuminderived AGEs as a potent contributor to adipocyte dysfunction [8]. Of note, an inverse association was found between circulating AGEs and fat mass in adults [26] and the authors explained their intriguing observation by AGE accumulation in fat tissues or altered adipocyte AGE metabolism [26]. In addition, unpublished data from our group revealed that albumin modifications in the plasma of diabetic mice resembled those typically found in diabetic patients, i.e. in terms of the degree of glycation, carbonylation and AGE levels. In the present study, enhanced ROS formation in adipose tissue of diabetic mice was reproduced by the incubation of 3T3L1 mouse adipocytes exposed to glycated albumin. Here our findings established that glycated albumin exposure triggered increased ROS production together with attenuated adipocyte cell viability. Thus it is likely that higher AGE levels with diabetes may be a key mediator of increased oxidative stress in adipoyctes and damaging downstream effects. In addition, oxidative stress can also fuel AGE generation thus establishing a vicious metabolic cycle [27] that can further exacerbate adipocyte dysfunction. However, further studies are required to clarify this. In summary, our study reveals novel insights into redox imbalance in adipocytes of diabetic/obese mice and highlights the role of AGEs (especially glycated albumin) as a putative contributor to adipocyte dysfunction.

\section{Conflict of interest}

Authors have no interest conflict to declare.

\section{Author contributions}

FB: acquisition of data; drafting the article, final approval.

ND: acquisition of data; drafting the article, final approval.

DG: acquisition of data; drafting the article, final approval.

PR: acquisition of data; drafting the article, final approval.

MFE: conception and design of the study, drafting the article, final approval.

EB: conception and design of the study, drafting the article, final approval.

\section{Acknowledgments}

This work was supported by the Ministère de l'Enseignement Supérieur et de la Recherche, the Université de La Réunion and by the Conseil régional de La Réunion, France and Europe (« Redox project »). FB is recipient of a fellowship from the Conseil Régional de La Réunion, France and Europe.

\section{References}

[1] H. Sies, Oxidative stress: a concept in redox biology and medicine, Redox Biol 4 (2015) 180-183.

[2] K.J. Davies, Degradation of oxidized proteins by the 20S proteasome, Biochimie 83 (2001) 301-310.

[3] W. Droge, Free radicals in the physiological control of cell function, Physiol Rev. 82 (2002) 47-95.

[4] N. Houstis, E.D. Rosen, E.S. Lander, Reactive oxygen species have a causal role in multiple forms of insulin resistance, Nature 440 (2006) 944-948.

[5] A. Jankovic, A. Korac, B. Buzadzic, V. Otasevic, A. Stancic, A. Daiber, B. Korac, Redox implications in adipose tissue (dys)function-a new look at old acquaintances, Redox Biol. 6 (2015) 19-32.

[6] S. Furukawa, et al., Increased oxidative stress in obesity and its impact on metabolic syndrome, J. Clin. Invest. 114 (2004) 1752-1761.

[7] A. Diaz-Ruiz, et al., Proteasome dysfunction associated to oxidative stress and proteotoxicity in adipocytes compromises insulin sensitivity in human obesity, Antioxid. Redox Signal 23 (2015) 597-612.

[8] F. Boyer, J.B. Vidot, A.G. Dubourg, P. Rondeau, M.F. Essop, E. Bourdon, Oxidative stress and adipocyte biology: focus on the role of AGEs, Oxid. Med. Cell Longev. 2015 (2015) 534873.

[9] G.L. Ellman, Tissue sulfhydryl groups, Arch. Biochem. Biophys. 82 (1959) $70-77$.

[10] A.L. Tappel, Glutathione peroxidase and hydroperoxides, Methods Enzymol. 52 (1978) 506-513.

[11] M. Roche, P. Rondeau, N.R. Singh, E. Tarnus, E. Bourdon, The antioxidant properties of serum albumin, FEBS Lett. 582 (2008) 1783-1787.

[12] K. Saotome, H. Morita, M. Umeda, Cytotoxicity test with simplified crysta violet staining method using microtitre plates and its application to injection drugs, Toxicol In Vitro 3 (1989) 317-321.

[13] J. Baraka-Vidot, A. Guerin-Dubourg, F. Dubois, B. Payet, E. Bourdon, P. Rondeau, New insights into deleterious impacts of in vivo glycation on albumin antioxidant activities, Biochim. Biophys. Acta 1830 (2013) 3532-3541.

[14] S. Chesne, P. Rondeau, S. Armenta, E. Bourdon, Effects of oxidative modifications induced by the glycation of bovine serum albumin on its structure and on cultured adipose cells, Biochimie 88 (2006) 1467-1477.

[15] N.R. Singh, P. Rondeau, L. Hoareau, E. Bourdon, Identification of preferential protein targets for carbonylation in human mature adipocytes treated with native or glycated albumin, Free Radic. Res. 41 (2007) 1078-1088.

[16] M. Le Pecheur, E. Bourdon, E. Paly, L. Farout, B. Friguet, J. London, Oxidized SOD1 alters proteasome activities in vitro and in the cortex of SOD1 overexpressing mice, FEBS Lett. 579 (2005) 3613-3618.

[17] E. Bourdon, D. Blache, The importance of proteins in defense against oxidation, Antioxid. Redox Signal 3 (2001) 293-311.

[18] M. Blatnik, S.R. Thorpe, J.W. Baynes, Succination of proteins by fumarate: mechanism of inactivation of glyceraldehyde-3-phosphate dehydrogenase in diabetes, Ann. N. Y. Acad. Sci. 1126 (2008) 272-275.

[19] S.A. Thomas, K.B. Storey, J.W. Baynes, N. Frizzell, Tissue distribution of S-(2succino)cysteine (2SC), a biomarker of mitochondrial stress in obesity and diabetes, Obes. (Silver Spring) 20 (2012) 263-269.

[20] N. Frizzell, M. Rajesh, M.J. Jepson, R. Nagai, J.A. Carson, S.R. Thorpe, J.W. Baynes, Succination of thiol groups in adipose tissue proteins in diabetes: succination inhibits polymerization and secretion of adiponectin, J. Biol. 
Chem. 284 (2009) 25772-25781.

[21] G. Murdolo, D. Bartolini, C. Tortoioli, M. Piroddi, L. Iuliano, F. Galli, Lipokines and oxysterols: novel adipose-derived lipid hormones linking adipose dysfunction and insulin resistance, Free Radic. Biol. Med. 65 (2013) 811-820.

[22] K. Dasuri, L. Zhang, P. Ebenezer, S.O. Fernandez-Kim, A.J. Bruce-Keller L.I. Szweda, J.N. Keller, Proteasome alterations during adipose differentiation and aging: links to impaired adipocyte differentiation and development of oxidative stress, Free Radic. Biol. Med. 51 (2011) 1727-1735.

[23] S.S. Wing, The UPS in diabetes and obesity, BMC Biochem. 9 (Suppl 1) (2008) S6.
[24] F. Boyer, P. Rondeau, E. Bourdon, Hyperglycemia induces oxidative damage in SW872 cells, Arch. Med. Biomed. Res. 1 (2014) 66-78.

[25] M. Pajares, et al., Redox control of protein degradation, Redox Biol. 6 (2015) 409-420.

[26] R.D. Semba, L. Arab, K. Sun, E.J. Nicklett, L. Ferrucci, Fat mass is inversely associated with serum carboxymethyl-lysine, an advanced glycation end product, in adults, J. Nutr. 141 (2011) 1726-1730.

[27] R.F. Mapanga, M.F. Essop, Damaging effects of hyperglycemia on cardiovascular function: spotlight on glucose metabolic pathways, Am. J. Physiol. Heart Circ. Physiol. 310 (2016) H153-H173. 